\title{
EFFECTS OF VARIOUS FLOW TYPES ON MATERNAL HEMODYNAMICS DURING FETAL BYPASS: IS THERE NITRIC OXIDE RELEASE DURING PULSATILE PERFUSION?
}

\author{
Catherine Vedrinne, $\mathrm{MD}^{\mathrm{a}}$ \\ François Tronc, MD ${ }^{\mathbf{b}}$ \\ Stéphane Martinot, $\mathrm{MVD}^{\mathrm{c}}$ \\ Jacques Robin, $\mathrm{MD}^{\mathrm{b}}$ \\ Claude Garhib $^{\mathrm{d}}$ \\ Jean Ninet, $\mathrm{MD}^{\mathrm{b}}$ \\ Jean Jacques Lehot, MD \\ Michel Franck, MVD \\ Gérard Champsaur, $\mathrm{MD}^{\mathrm{b}}$
}

\begin{abstract}
Objective: This study investigates the role of various flow conditions on maternal hemodynamics during fetal cardiopulmonary bypass. Methods: Normothermic fetal bypass was conducted under pulsatile, or steady flow, for a 60-minute period. Fetal lamb preparations were randomly assigned to 1 of the 3 groups: steady flow ( $n=7$ ), pulsatile flow $(n=7)$, or pulsatile blocked flow bypass $(n=7)$, where fetuses were perfused with $N^{\omega}$-nitro-Larginine after the first $\mathbf{3 0}$ minutes of pulsatile flow to assess the potential role of endothelial autacoids. Results: Maternal oximetry and pressures remained unchanged throughout the procedure. Under fetal pulsatile flow, maternal cardiac output increased after 20 minutes of bypass and remained significantly higher than under steady flow at minute $30\left(8.8 \pm 0.7 \mathrm{~L} \cdot \mathrm{min}^{-1}\right.$ vs $5.9 \pm 0.5 \mathrm{~L} \cdot \mathrm{min}^{-1}, P=.02$ ). Maternal cardiac output in the pulsatile group also remained higher than in both steady and pulsatile blocked flow groups, reaching respectively $8.7 \pm 0.9 \mathrm{~L} \cdot \mathrm{min}^{-1}$ vs $5.8 \pm 0.4 \mathrm{~L} \cdot \mathrm{min}^{-1}(P=$ $.02)$ and $5.9 \pm 0.3 \mathrm{~L} \cdot \mathrm{min}^{-1}(P=.01)$ at minute 60 . Maternal systemic vascular resistances were significantly lower under pulsatile than under steady flow after 30 minutes and until the end of bypass (respectively, $9.1 \pm$ $0.6 \mathrm{IU}$ vs $12.7 \pm 1.1 \mathrm{IU}, P=.02$ and $8.9 \pm 0.5 \mathrm{IU}$ vs $12.9 \pm 1.2 \mathrm{IU}, P=.01$ ). Infusion of $N^{\omega}$-nitro-L-arginine was followed by an increase in systemic vascular resistances from $9.3 \pm 0.7 \mathrm{IU}$, similar to that of the pulsatile group, to $13.5 \pm 1 \mathrm{IU}$ at 60 minutes, similar to that of the steady flow group. Conclusions: Maternal hemodynamic changes observed under fetal pulsatile flow are counteracted after infusion of $N^{\omega}$-nitro-L-arginine, suggesting nitric oxide release from the fetoplacental unit under pulsatile fetal flow conditions. (J Thorac Cardiovasc Surg 1998;116:432-9)
\end{abstract}

$\mathrm{D}$ uring normal pregnancy, maternal hemodynamic changes are well documented, such as the increase in cardiac output (CO), kidney blood flow, and glomerular filtration. ${ }^{1}$ The observed reduction in blood pressure is caused by vasodilation and changes of the vascular tone and reactivity, medi-

From the Departments of Anesthesia and Intensive Care Medicine in Cardiovascular Surgery and of Cardiovascular Surgery, ${ }^{b}$ Louis Pradel Cardiologic Hospital, the Physiology Laboratory, Claude Bernard University, ${ }^{d}$ and the National Veterinary School, ${ }^{c}$ Lyon, France.

Supported in part by a research contract (JE 1949) with Claude Bernard University, Lyon, France.

Received for publication Dec. 22, 1997; revisions requested March 25, 1998; revisions received April 27, 1998; accepted for publication April 28, 1998.

Address for reprints: C. Vedrinne, MD, Hopital Cardiologique Louis Pradel, 59 Boulevard Pinel, 69003, Lyon, France.

Copyright (C) 1998 by Mosby, Inc.

$0022-5223 / 98 \$ 5.00+0 \quad \mathbf{1 2 / 1 / 9 1 3 6 9}$ ated by gestational hormonal activity like the production of vasodilator prostaglandins by the uteroplacental unit or the decrease in vascular reaction to vasoconstrictive factors like angiotensin. ${ }^{2,3}$ Interactions between maternal and fetal circulations are exacerbated under pathologic conditions like hypertension and preeclampsia, associated with increased risks to both the mother and the fetus. Similarly fetal distress may result from unbalanced placental flows under maternal bypass, which is sometimes performed for the correction of maternal valvular heart disease during pregnancy. ${ }^{4}$ On the other hand, given the recent improvements in antenatal diagnosis, some congenital heart defects might be amenable to intrauterine correction, necessitating the establishment of fetal cardiopulmonary bypass. Experimentally, fetal bypass is usually poorly tolerated, unless some pharmacologic support is used. ${ }^{5-9}$

In previous experiments, we had demonstrated that the use of pulsatile flow bypass may help to 


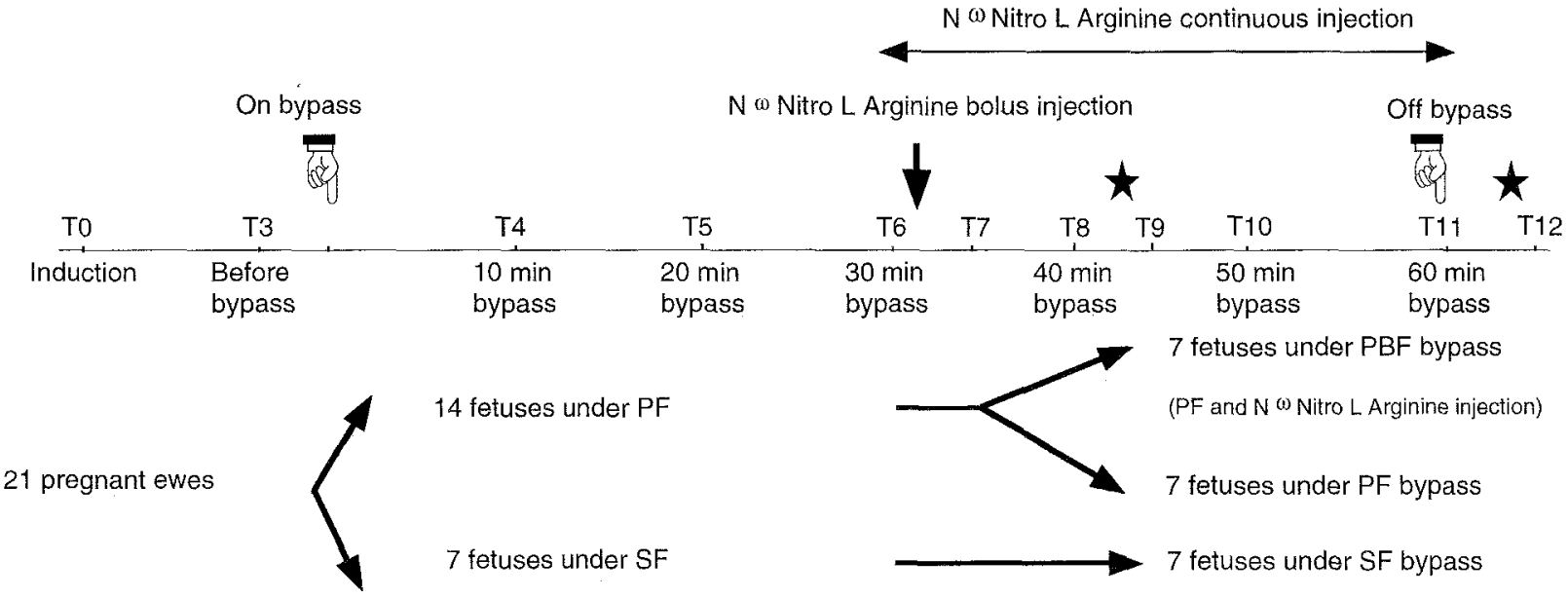

Fig. 1. Experimental protocol. Administration of ACH to fetuses after $40 \mathrm{~min}$ of bypass (T8) and to ewes after the end of fetuses bypass (T11). $\downarrow$ N-NA injection in the PBF group after 30 minutes of bypass.

prevent the onset of fetal hypoxia in this setting. ${ }^{10,11}$ More specifically, we had commonly observed that during a 30-minute period of fetal bypass, maternal blood pressure was usually lower under pulsatile flow than under steady flow. But in this fetal lamb preparation, the maternal hemodynamic status was not precisely monitored, particularly maternal blood flows and resistances. Finally, to the best of our knowledge, the effects of fetal bypass on maternal hemodynamics have not been investigated.

The aim of the present study was to assess the effects of fetal pulsatile flow as compared with fetal steady flow bypass on maternal hemodynamics. Because stimulation of nitric oxide (NO) endothelial cell synthesis has been well described under high shear stress situations in arteries, like during pulsatile flow, ${ }^{12-14}$ the secondary end point of the study was to evaluate the potential impact of endothelium-derived vasoactive substance release on maternal hemodynamic parameters under various fetal bypass flow conditions.

\section{Materials and methods}

All procedures and protocols performed in this study were approved by the local Animal Care Committee and in compliance with the Guide of the National Veterinary School for Laboratory animal studies.

Anesthesia and hemodynamic monitoring. Twenty-one mixed-breed "Grivette" ewes between 125 and 142 days gestation were fasted for 24 to 48 hours before the operation. The animals were placed in the supine position on an operating table after induction of anesthesia with diazepam $\left(0.25 \mathrm{mg} \cdot \mathrm{kg}^{-1}\right)$ and ketamine $\left(5 \mathrm{mg} \cdot \mathrm{kg}^{-1}\right)$ intravenously administered in the jugular vein. Ewes were endotracheally intubated and connected to a volumecycled respirator (MMS 107 ventilator; Bioms, Pau, France) with a 10 -cycle/min respiratory rate and a 15 $\mathrm{ml} \cdot \mathrm{kg}^{-1}$ tidal volume, with nitrous oxide/oxygen simultaneously administered at a flow rate intended to keep the arterial oxygen saturation at $99 \%$ and the arterial carbon dioxide tension $\left(\mathrm{PCO}_{2}\right)$ within normal limits. Anesthesia was maintained with $1 \%$ to $1.5 \%$ inspired halothane supplied by a Fluotec vaporizer (Ohmeda Health Care, West Yorkshire, England). Expired gases (oxygen, carbon dioxide, NO, halothane) were continuously monitered using a Hewlett-Packard analyzer (HP M1015B; Bron, France) to adjust volume and percentage of inspired gases for an optimal ventilation.

Sheep were instrumented with a pulmonary artery flow-directed thermodilution catheter (Abbott Laboratories, Rungis, France) inserted percutaneously via an $8 \mathrm{~F}$ introducer set (USCI Hemaquet, Baxter, Galway, Ireland) in the right jugular vein and up to the pulmonary artery. An arterial line was introduced in the femoral artery through a cutdown for maternal blood pressure monitoring and gas sampling. $\mathrm{CO}$ was measured with an Oxymetrix 3 computer (Abbott Laboratorics, Rungis, France) by the thermodilution technique, performed in triplicate, with a $10 \mathrm{ml}$ cold crystalloid bolus injection, recording the average value CO. Systemic and pulmonary vascular resistances were calculated by standard formulas. Another large-bore intravenous catheter (16-gauge) was inserted in the left jugular vein for fluid infusion to maintain adequate uterine perfusion and to avoid fetal and maternal hypoglycemia. Maternal and fetal hemodynamic parameters were continuously monitored with Baxter transducers (Uniflow pressure set; Baxter Healthcare, Maurepas, France) and a multichannel recorder (Kone Corporation Instrument Division, Espoo, Finland). Blood gases sampled from maternal femoral artery were 
Table I. Values of maternal blood gasses before and during bypass

\begin{tabular}{|c|c|c|c|c|c|}
\hline Time & Group & $p H$ & $\begin{array}{c}\mathrm{PaO}_{2} \\
(\mathrm{~mm} \mathrm{Hg}) \\
\end{array}$ & $\begin{array}{c}\mathrm{PaCO}_{2} \\
(\mathrm{~mm} \mathrm{Hg}) \\
\end{array}$ & $\mathrm{SaO}_{2}(\%)$ \\
\hline \multirow[t]{3}{*}{ After induction (T0) } & SF & $7.38 \pm 0.02$ & $169 \pm 37$ & $32 \pm 4$ & $94 \pm 3$ \\
\hline & $\mathrm{PF}$ & $7.35 \pm 0.03$ & $149 \pm 20$ & $34 \pm 3$ & $97 \pm 1$ \\
\hline & $\mathrm{PBF}$ & $7.39 \pm 0.04$ & $165 \pm 20$ & $35 \pm 3$ & $98 \pm 1$ \\
\hline \multirow[t]{3}{*}{ Before bypass (T3) } & $\mathrm{SF}$ & $7.42 \pm 0.07$ & $148 \pm 37$ & $36 \pm 5$ & $94 \pm 2$ \\
\hline & PF & $7.38 \pm 0.05$ & $119 \pm 12$ & $35 \pm 5$ & $96 \pm 1$ \\
\hline & $\mathrm{PBF}$ & $7.41 \pm 0.04$ & $161 \pm 25$ & $39 \pm 4$ & $97 \pm 1$ \\
\hline \multirow[t]{3}{*}{ 10-Min bypass (T4) } & $\mathrm{SF}$ & $7.46 \pm 0.07$ & $144 \pm 29$ & $31 \pm 6$ & $96 \pm 2$ \\
\hline & $\mathrm{PF}$ & $7.37 \pm 0.07$ & $128 \pm 16$ & $36 \pm 6$ & $96 \pm 1$ \\
\hline & $\mathrm{PBF}$ & $7.41 \pm 0.04$ & $149 \pm 23$ & $37 \pm 3$ & $97 \pm 1$ \\
\hline \multirow[t]{3}{*}{ 30-Min bypass (T6) } & $\mathrm{SF}$ & $7.46 \pm 0.07$ & $167 \pm 38$ & $33 \pm 6$ & $96 \pm 2$ \\
\hline & PF & $7.37 \pm 0.06$ & $147 \pm 33$ & $36 \pm 6$ & $97 \pm 1$ \\
\hline & PBF & $7.42 \pm 0.03$ & $144 \pm 26$ & $35 \pm 2$ & $97 \pm 1$ \\
\hline \multirow[t]{3}{*}{ 40-Min bypass (T8) } & SF & $7.48 \pm 0.08$ & $162 \pm 35$ & $31 \pm 7$ & $96 \pm 2$ \\
\hline & $\mathrm{PF}$ & $7.37 \pm 0.06$ & $139 \pm 31$ & $38 \pm 7$ & $96 \pm 1$ \\
\hline & $\mathrm{PBF}$ & $7.42 \pm 0.03$ & $134 \pm 23$ & $37 \pm 2$ & $96 \pm 1$ \\
\hline \multirow[t]{3}{*}{ 60-Min bypass (T11) } & $\mathrm{SF}$ & $7.48 \pm 0.08$ & $165 \pm 34$ & $30 \pm 7$ & $96 \pm 2$ \\
\hline & PF & $7.39 \pm 0.05$ & $145 \pm 33$ & $33 \pm 5$ & $97 \pm 1$ \\
\hline & PBF & $7.41 \pm 0.04$ & $135 \pm 26$ & $35 \pm 2$ & $96 \pm 1$ \\
\hline
\end{tabular}

All data are mean \pm SEM.

immediately analyzed $\left(\mathrm{PaO}_{2}, \mathrm{PaCO}_{2}\right.$, and $\mathrm{pH}$ values $)$ on a Radiometer 2400 gas analyzer (ABL 330, Radiometer Copenhagen, Copenhagen, Denmark).

Hemodynamic and oximetric data were collected after induction of anesthesia (T0), 10 minutes before onset of bypass (T3), every 10 minutes after the initiation of bypass, 5 minutes after the fetal $N^{\omega}{ }^{\omega}$-nitro-L-arginine (N-NA) bolus injection (T7), and immediately after fetal (T9) and maternal injection (T12) of acetylcholine chloride (ACH). Measurement of fetal urinary excretion of NO metabolite and of maternal venous endothelin- 1 concentration were performed in the 3 groups at the end of the procedure. Hemoglobin concentration was measured on an hemoglobin photometer (Hemocue, Ängelholm, Sweden).

Surgical procedure. After the uterus was exposed through a low midline laparotomy and a small hysterotomy, fetal surgery was carried out according to a previously described technique. ${ }^{10}$ Ketamine $(50 \mathrm{mg})$ was administered intramuscularly to the fetus. Through a fetal neck incision, catheters were inserted into the common carotid artery for blood pressure monitoring and blood sampling and into the jugular vein for fetal perfusion. After a fetal midline sternotomy, normothermic bypass was instituted between pulmonary artery and right atrium cannulation. The bypass circuit consisted of a bubble oxygenator (Optiflow II; Cobe Laboratories Inc., Lakewood, Colo.) and a venous reservoir primed with $700 \mathrm{ml}$ of freshly drawn heparinized adult sheep donor blood diluted with $300 \mathrm{ml}$ of Ringer's lactate. Bypass was conducted for a 60 -minute period with a centrifugal pump (Delphin II centrifugal system; Sarns/3M Health Care, Ann Arbor, Mich.) set to deliver either pulsatile or steady flow. After the onset of bypass, the fetal heart was electrically fibrillated to rule out any contribution of the heart to the bypass flow and pulsatility. In each experiment the pump flow was adjusted to deliver a fetal mean blood pressure within the physiologic range of 45 to 50 $\mathrm{mm} \mathrm{Hg}$. After cessation of bypass, the fetus was killed and weighed. A fetus urinary sample was collected through a bladder puncture. The ewe was then allowed to recover under antibiotic prophylaxis, associating penicillin and colistin intramuscularly delivered.

Drug preparation. Immediately before each experiment, N-NA, $450 \mathrm{mg}$ (Sigma Chemical, St. Quentin Falavier, France) was dissolved in a solution of $45 \mathrm{ml}$ of $0.9 \%$ sodium chloride $(\mathrm{NaCl})$. Acetylcholine chloride, 10 $\mathrm{mg}$ (Sigma Chemical) was diluted in one liter of $\mathrm{NaCl}, 1$ $\mathrm{ml}$ representing $10 \mu \mathrm{g}$.

Endothelin-1 and NO metabolite measurements. Arterial blood samples $(4.5 \mathrm{ml})$ were withdrawn into EDTA glass tubes after the end of bypass in all animals and immediately stored in ice. Blood samples were then centrifuged at $1250 \mathrm{~g}$ and $4^{\circ} \mathrm{C}$ for 10 minutes, drawn up, and stored at $-20^{\circ} \mathrm{C}$ until assayed. Plasma levels of endothelin-1 were determined by radioimmunoassay. ${ }^{15}$ Fetal urinary samples were immediately stored at $-20^{\circ} \mathrm{C}$. Nitrate assays were measured in fetal urine by dilution with distilled water and incubation with nitrate reductase and flavine adenosine. ${ }^{16}$

Protocol. The ewes $(n=21)$ were randomly allocated into 1 of the 3 groups, according to the type of fetal bypass, either steady flow (SF group, $n=7$ ), pulsatile flow (PF group, $n=7$ ), or pulsatile blocked flow (PBF group, $n=7$ ). To test a potential modification of the vascular endothelium release of vasoactive substances under pulsatile flow conditions (Fig. 1), fetuses in the third group were perfused with N-NA, a stereospecific endotheliumderived relaxing factor synthesis inhibitor. ${ }^{17}$ Fetuses in the PBF group received a bolus injection of the diluted N-NA solution $\left(20 \mathrm{mg} \cdot \mathrm{kg}^{-1}\right)$, slowly injected in the jugular vein after 30 minutes of bypass, followed by a $20 \mathrm{mg} \cdot \mathrm{kg}^{-1} \cdot \mathrm{hr}^{-1}$ continuous infusion for the next 30 minutes to the end of bypass. In previous studies, this dose had been shown to block NO production. ${ }^{17}$ To determine the effectiveness of 
Table II. Maternal hemodynamic

\begin{tabular}{|c|c|c|c|c|c|c|}
\hline & Group & $H R$ & $\begin{array}{c}M A B P \\
(m m H g)\end{array}$ & $\begin{array}{c}\text { CVP } \\
(m m H g)\end{array}$ & $\begin{array}{c}M P A P \\
(m m H g)\end{array}$ & $\begin{array}{c}P A O P \\
(m m \mathrm{Hg})\end{array}$ \\
\hline \multirow{3}{*}{ After induction (T0) } & SF & $108 \pm 9$ & $84 \pm 4$ & $9 \pm 1$ & $16 \pm 1$ & $11 \pm 1$ \\
\hline & $\mathrm{PF}$ & $102 \pm 2$ & $86 \pm 5$ & $8 \pm 1$ & $16 \pm 1$ & $10 \pm 1$ \\
\hline & PBF & $113 \pm 9$ & $83 \pm 4$ & $9 \pm 1$ & $17 \pm 2$ & $11 \pm 1$ \\
\hline \multirow[t]{3}{*}{ Before bypass (T3) } & SF & $119 \pm 13$ & $79 \pm 3$ & $7 \pm 1$ & $16 \pm 1$ & $8 \pm 1$ \\
\hline & $\mathrm{PF}$ & $110 \pm 9$ & $88 \pm 5$ & $7 \pm 1$ & $14 \pm 1$ & $10 \pm 1$ \\
\hline & PBF & $116 \pm 9$ & $84 \pm 5$ & $6 \pm 1$ & $17 \pm 2$ & $12 \pm 2$ \\
\hline \multirow{3}{*}{ 10-Min bypass (T4) } & $\mathrm{SF}$ & $118 \pm 11$ & $78 \pm 3$ & $6 \pm 5$ & $15 \pm 1$ & $9 \pm 1$ \\
\hline & $\mathrm{PF}$ & $113 \pm 10$ & $84 \pm 5$ & $6 \pm 1$ & $16 \pm 1$ & $10 \pm 1$ \\
\hline & PBF & $116 \pm 7$ & $83 \pm 5$ & $6 \pm 1$ & $15 \pm 1$ & $9 \pm 1$ \\
\hline \multirow[t]{3}{*}{ 30-Min bypass (T6) } & SF & $122 \pm 10$ & $79 \pm 3$ & $6 \pm 1$ & $14 \pm 1$ & $9 \pm 1$ \\
\hline & $\mathrm{PF}$ & $118 \pm 5$ & $85 \pm 6$ & $7 \pm 1$ & $16 \pm 2$ & $10 \pm 1$ \\
\hline & PBF & $119 \pm 9$ & $85 \pm 5$ & $7 \pm 1$ & $14 \pm 1$ & $10 \pm 1$ \\
\hline \multirow[t]{3}{*}{ 40-Min bypass (T8) } & SF & $118 \pm 5$ & $79 \pm 3$ & $7 \pm 1$ & $15 \pm 1$ & $8 \pm 1$ \\
\hline & $\mathrm{PF}$ & $122 \pm 10$ & $81 \pm 6$ & $7 \pm 1$ & $16 \pm 2$ & $10 \pm 1$ \\
\hline & PBF & $118 \pm 12$ & $85 \pm 6$ & $7 \pm 1$ & $15 \pm 1$ & $10 \pm 1$ \\
\hline \multirow[t]{3}{*}{ 60-Min bypass (T11) } & SF & $119 \pm 9$ & $79 \pm 3$ & $7 \pm 1$ & $13 \pm 2$ & $10 \pm 1$ \\
\hline & PF & $114 \pm 10$ & $82 \pm 6$ & $7 \pm 1$ & $15 \pm 1$ & $8 \pm 1$ \\
\hline & PBF & $120 \pm 8$ & $87 \pm 6$ & $8 \pm 1$ & $15 \pm 1$ & $10 \pm 1$ \\
\hline
\end{tabular}

All data are mean \pm SEM.

$H R$, Heart rate; $C V P$, central venous pressure; $M P A P$, mean pulmonary artery blood pressure; $P A O P$, pulmonary artery occlusive pressure.

subsequent maternal and fetal NO blockade caused by N-NA, the hemodynamic response to an intact endotheliumdependent vasodilator, such as $\mathrm{ACH}(45 \mu \mathrm{g})$, was evaluated: fetal ACH jugular venous injection was performed immediately after minute 40 of bypass, whereas maternal $\mathrm{ACH}$ venous injection was made shortly after the end of bypass to prevent maternal hemodynamic destabilization.

Statistical analysis. Data were stored on a spreadsheet database with a Power Macintosh 7600/132 (Apple Computers, Inc., Cupertino, Calif.) and analyzed with a statistical package (Statview; Abacus Concept, Inc., Berkeley, Calif.). Values were expressed as mean \pm SEM. A repeated-factor ANOVA test was made to compare one after the other, all the hemodynamic variables and all the blood gas measurements in the 3 group with a PLSD Fisher test if necessary. When intergroup variability was assessed by repcated-measures analysis of variance, we performed the nonparametric test of Kruskal and Wallis on specific means at T0, T3, T4, T6, 40 minutes of bypass (T8), and the end of bypass (T11) with a post hoc testing of Bonferroni/Dunn. Nonparametric Wilcoxon test was used to compare paired values and to determine the effect of N-NA or $\mathrm{ACH}$ infusion. Plasma maternal endothelin levels and urinary nitrate and nitrite values were compared with the Kruskal-Wallis test. Statistical significance was established at the 5\% level.

\section{Results}

The 3 groups were comparable as regard to the average weight of ewes $(55 \pm 6 \mathrm{~kg})$ and fetuses $(3.9 \pm 0.2 \mathrm{~kg})$ and the gestation weight $(7.8 \pm 3.3$ $\mathrm{kg})$ and mean number of fetuses $(2 \pm 0.1)$.

The maternal values of arterial $\mathrm{pH}, \mathrm{PCO}_{2}, \mathrm{PO}_{2}$, and oxyhemoglobin saturation were not significantly different between groups and within groups at any given time (Table I). After induction of anesthesia, the hemoglobin values were similar in the 3 groups $\left(7.5 \pm 0.2 \mathrm{~g} \cdot \mathrm{L}^{-1}\right)$, and remained stable throughout the experiment $\left(7.6 \pm 0.6 \mathrm{~g} \cdot \mathrm{L}^{-1}\right)$.

Pump flow was significantly different between the groups at T6 (SF $612 \pm 144 \mathrm{ml} \cdot \mathrm{min}$; PBF $987 \pm 228$ $\mathrm{ml} \cdot \min ; \mathrm{PF} 907 \pm 153 \mathrm{ml} \cdot \mathrm{min})$ and $\mathrm{T} 11(\mathrm{SF} 530 \pm$ $54 \mathrm{ml} \cdot \mathrm{min}$; PBF $607 \pm 117 \mathrm{ml} \cdot \mathrm{min} ; \mathrm{PF} 941 \pm 228$ $\mathrm{ml} \cdot \mathrm{min})$.

Maternal mean arterial blood pressure (MABP) in the PF group was similar to the 2 other groups in regard to repeated-factor ANOVA analysis. Other maternal hemodynamic variables remained stable throughout the procedure and whatever the fetal flow conditions: heart rate, right atrial pressure, pulmonary artery pressure, and pulmonary artery occlusive pressures (Table II).

Maternal $\mathrm{CO}$ under pulsatile flow started to differ from maternal $\mathrm{CO}$ under steady flow (Fig. 2) 20 minutes after the onset of fetal bypass (T5: 6.1 \pm 0.5 $\mathrm{L} \cdot \mathrm{min}^{-1}$ in SF vs $8.3 \pm 0.7 \mathrm{~L} \cdot \min ^{-1}$ in PF; $P=.07$ ) and became significantly different from SF after 30 minutes of bypass (T6: $5.9 \pm 0.5 \mathrm{~L} \cdot \mathrm{min}^{-1}$ in SF vs $8.8 \pm 0.7 \mathrm{~L} \cdot \mathrm{min}^{-1}$ in $\mathrm{PF} ; P=.01 ;$ and vs $7.69 \pm 0.9$ $\mathrm{L} \cdot \mathrm{min}^{-1}$ in PBF; $P=.05$ ). After T8 and until T11, maternal $\mathrm{CO}$ was significantly higher in the $\mathrm{PF}$ group than in the SF group (T11: $8.7 \pm 0.9 \mathrm{~L} \cdot \mathrm{min}^{-1}$ 


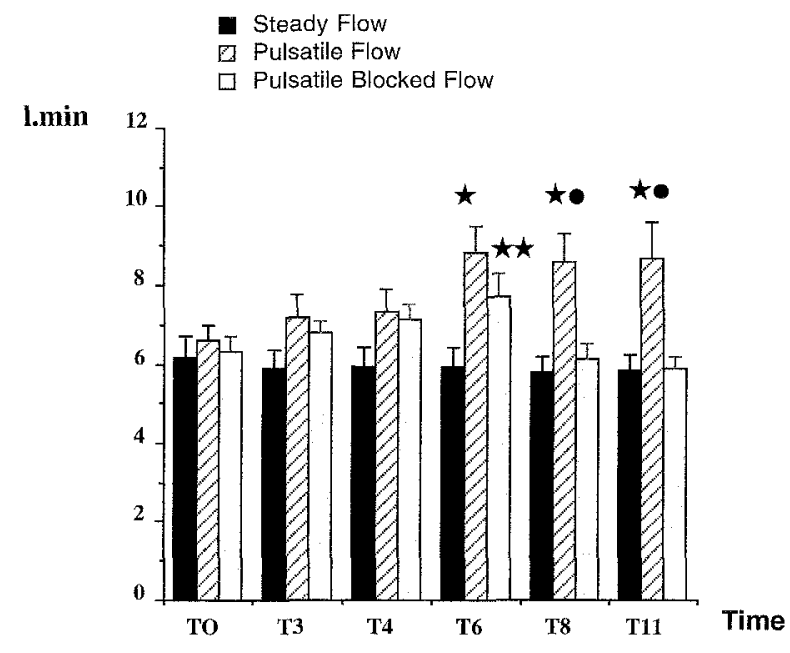

Fig. 2. Maternal CO $(\mathrm{L} \cdot \min )$, evolution, and between groups comparison: $\mathrm{T} 0$, induction, $\mathrm{T} 3$ before bypass; $\mathrm{T} 4=$ $10 \mathrm{~min} ; \mathrm{T} 6=30 \mathrm{~min} ; \mathrm{T} 8=40 \mathrm{~min} ; \mathrm{T} 11=60 \mathrm{~min}$ of bypass. $\star \mathrm{PF}$ versus $\mathrm{SF}$ group, $P<.05 . \star \star \mathrm{PBF}$ group versus SF group, $P<.05$. PF versus PBF group, $P<.05$.

vs $5.8 \pm 0.4 \mathrm{~L} \cdot \min ^{-1} ; P=.02$ ). In the PBF group a drop in maternal $C O$ values was observed after the N-NA injection (T7). After T8 and until T11, maternal $\mathrm{CO}$ in the PBF groups was similar to that of the SF group.

The difference in $\mathrm{CO}$ was linked to a significant decrease in systemic vascular resistances under pulsatile flow conditions. Whereas the systemic vascular resistances were similar at the induction of anesthesia (T0) and just before bypass (T3) (Fig. 3), they differed significantly in the PF versus the SF after 30 minutes (T6) up until the end of bypass (T11) (respectively, T6: $9.1 \pm 0.6 \mathrm{IU}$ vs $12.7 \pm 1.1 \mathrm{IU} ; P=$ .02 ; T11: $8.9 \pm 0.5 \mathrm{IU}$ vs $12.9 \pm 1.2 \mathrm{IU} ; P=.01$ ). After 30 minutes of pulsatile flow (T6), systemic vascular resistances in the PBF group were similar to those of the PF group but differed significantly from those of the SF group (T6: $9.3 \pm 0.7 \mathrm{IU}$ in PBF; $P=.01$ ). In the PBF group, a significant increase in systemic vascular resistances was observed 10 minutes after N-NA infusion (T8: $9.3 \pm$ $0.7 \mathrm{IU}$ to $12.9 \pm 0.9 \mathrm{IU} ; P=.05)$. They remained then similar to that of the SF group until the end of bypass (T11).

Pulmonary vascular resistances were not different between the groups (repeated-factor ANOVA) throughout the procedure.

The fetal bolus injection of N-NA performed 30 minutes after the initiation of bypass and followed

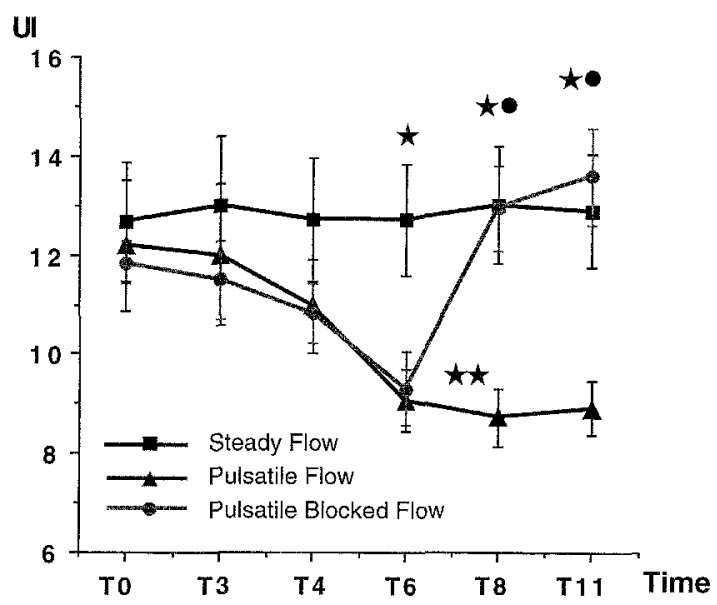

Fig. 3. Maternal systemic vascular resistances (IU), evolution, and between groups comparison: $\mathrm{T} 0$, induction, $\mathrm{T} 3$ before bypass; $\mathrm{T} 4=10 \mathrm{~min} ; \mathrm{T} 6=30 \mathrm{~min} ; \mathrm{T} 8=40 \mathrm{~min}$; $\mathrm{T} 11=60 \mathrm{~min}$ of bypass. $\star \mathrm{PF}$ versus $\mathrm{SF}$ group, $P<.05$. $\star \star \mathrm{PBF}$ group versus SF group, $P<.05$. $\bullet \mathrm{PF}$ versus $\mathrm{PBF}$ group, $P<.05$.

by a continuous infusion induced no instantaneous significant increase in systemic blood pressure (T7), neither in the ewes nor in the fetuses.

Maternal injection of $\mathrm{ACH}$ at the end of the bypass (T12) induced a significant decrease in maternal systemic blood pressure in the 3 groups (Table III). Conversely, fetal injection of $\mathrm{ACH}$ after minute 40 of bypass was followed by a significant drop in fetal systemic blood pressure in the $\mathrm{PF}$ group (T9, $P=.01$ ), a nonsignificant drop in fetal systemic blood pressure in the SF group, and no changes in fetal systemic blood pressure in the PBF group (Table III).

When comparing maternal endothelin-1 levels, there was no significant difference either intra- or intergroup (SF: $62.1 \pm 13.2 \mathrm{pg} \cdot \mathrm{ml}^{-1}$; PF: $42 \pm 4.8$ $\mathrm{pg} \cdot \mathrm{ml}^{-1}$; PBF: $41.6 \pm 14.9 \mathrm{pg} \cdot \mathrm{ml}^{-1}$ ).

Similarly urinary nitrate and nitrite values (SF: $450 \pm 110 \mu \mathrm{mol} \cdot \mathrm{L}^{-1} ; \mathrm{PF}: 546 \pm 54 \mu \mathrm{mol} \cdot \mathrm{L}^{-1}$; PBF: $571 \pm 85 \mu \mathrm{mol} \cdot \mathrm{L}^{-1}$ ) did not reach significant difference.

\section{Discussion}

In a previous study on a fetal lamb preparation undergoing 30 minutes of bypass, we had made the observation that maternal blood pressure under fetal pulsatile flow was usually lower than under fetal steady flow bypass. ${ }^{10}$ The pump flow was significantly higher in the pulsatile flow conditions, 
Table III. Effect on mean arterial pressure of ACH injection in ewes and fetuses

\begin{tabular}{|c|c|c|c|c|c|c|}
\hline & \multicolumn{3}{|c|}{ Ewes } & \multicolumn{3}{|c|}{ Fetuses } \\
\hline & $M A B P 1$ & $M A B P 2$ & $P$ & $M A B P I$ & $M A B P 2$ & $P$ \\
\hline SF & $76.2 \pm 3.8$ & $51.8 \pm 3.8$ & $<.004$ & $51.2 \pm 2.5$ & $46.5 \pm 2$ & NS \\
\hline PF & $84.9 \pm 4.6$ & $54 \pm 8.2$ & $<.0001$ & $52.7 \pm 1.6$ & $43.6 \pm 2$ & $<.005$ \\
\hline PBF & $86.6 \pm 7.9$ & $54.7 \pm 6.1$ & $<.0001$ & $49.8 \pm 1.0$ & $50.7 \pm 1.9$ & NS \\
\hline
\end{tabular}

All data are mean \pm SEM.

$M A B P 1$, Mean arterial blood pressure before $\mathrm{ACH}$ injection; $M A B P 2$, mean arterial blood pressure after ACH injection.

and the role of fetal or placental vascular mediator release on fetus hemodynamics had been suggested. The aim of the present study was to confirm the effects of fetal blood flow characteristics on maternal blood pressure and to assess maternal blood flow and resistances, which were not available in the previous study. Because we had demonstrated in another study ${ }^{11}$ that there was a release of NO from the fetal endothelium under pulsatile flow bypass, we hypothesized that observed maternal effects, if any, might be due to fetal or fetoplacental unit synthesis of endothelial autacoids in response to different fetal perfusion conditions.

The use of pulsatile flow during standard cardiac operations remains controversial, but several authors demonstrated a better tissue perfusion, ${ }^{18}$ a lower hormonal stress response or "whole body inflammatory response,"19 and a reduction in the occurrence of postoperative hypertension. ${ }^{20,21}$ In this study the maternal hemodynamic differences observed between pulsatile and steady flow fetal bypass groups disappeared after fetal infusion of N-NA, a highly specific inhibitor of NO synthesis. ${ }^{17}$ This effect suggests the release of $\mathrm{NO}^{22}$ during fetal pulsatile flow bypass.

NO is synthesized from L-arginine released by endothelial cells, and it relaxes vascular smooth muscle by inducing production of intracellular cyclic guanosine monophosphate. NO has only a local effect because it is inactivated by hemoglobin and thus disappears within a few seconds. However, its constant synthesis and release by endothelial cells maintains a constant vasodilator tone on the whole vascular system. ${ }^{22}$ At this moment, there is no direct evidence that bypass changes modify NO production. It has been demonstrated in vitro in isolated arterial segments that high shear stress in arterial wall stimulates the endothelial cell synthesis of NO. ${ }^{13,14}$ Thus blood vessels are submitted on 1 hand to mechanical stress related to the transmural pressure exerted on their walls and on the other hand to blood flow changes. ${ }^{23}$ An increase in blood flow is followed by relaxation of the vessel, which tends to counteract the shear stress, through an increase in NO production and a decrease in endothelin-1 liberation. ${ }^{24}$

Normally the placenta receives $40 \% \quad(200$ $\mathrm{ml} \cdot \mathrm{kg}^{-1} \cdot \mathrm{min}^{-1}$ ) of the total biventricular fetal output $\left(450 \mathrm{ml} \cdot \mathrm{kg}^{-1} \cdot \mathrm{min}^{-1}\right),{ }^{25}$ and pulsatile bypass was found to maintain the placental perfusion within physiologic limits in our previous study. ${ }^{10}$ Moreover, plasma levels, urinary excretion, and metabolic production of cyclic guanosine monophosphate are increased in gravid rats and Conrad and colleagues ${ }^{16}$ postulated that endogenous NO may mediate this changes. The authors also identified an increased NO biosynthesis during pregnancy ${ }^{26} \mathrm{NO}$ synthase enzyme was recently identified in the human placental villous vascular tree, and NO appears to be involved in maintaining basal tone and alleviating the effect of vasoconstrictors on fetoplacental circulation. ${ }^{27}$ So, the earlier experiences under steady flow bypass in fetal lambs demonstrated fetal death to be related to hypercapnia and hypoxia, secondary to placental vasoconstriction. ${ }^{8,9}$ Pulsatile flow may have acted as a continuous stimulus on the endothelial cells thus upholding the usual high placental production level of NO. It remains unclear why the apparently lower fetal urinary nitrate level in the SF group than in either PF or PBF group did, however, not reach significance; but maternal blood and urinary nitrate measurements were not available at the time of the study.

$\mathrm{ACH}$ injection in the fetus induced a significant decrease in MABP only in the PF group and a nonsignificant drop in the SF group. These findings support the hypothesis that under PF the basal production level of NO is higher than in the 2 other groups: despite the circuit priming volume and hemodilution, the injection of endothelium-dependent $\mathrm{ACH}$ may have induced a significant liberation of NO generating the blood pressure drop. No 
changes in systemic blood pressure were observed in the PBF group, confirming in this case the efficient blockade of fetal NO synthase.

Maternal ACH injection induced a significant drop in maternal MABP in all 3 groups of animals. Even though N-NA may cross the fetoplacental barrier $^{28}$ and although it is conceivable that the bolus administration of $\mathrm{ACH}$ may have overwhelmed the inhibitory effects of fetal N-NA injection, maternal hemodynamic changes in the PBF group could not be explained only by maternal NO synthesis inhibition, raising the issue of other vasoactive substances release during pulsatile perfusion.

Endothelin-1 is a powerful long-acting calciumdependent vasoconstrictor produced by endothelial cells. $^{29}$ Conventional cardiopulmonary bypass increases the plasma endothelin- 1 level. ${ }^{20}$ Endothelin-1 binding sites have also been described ${ }^{30}$ in trophoblast and in human placental blood vessels. In the pregnant rat, endothelin-1 has been described either as a vasodilator or a vasoconstrictor agent, depending on the injection dose, the pregnant term, and the nature of endothelin receptor affinity. However in this study, endothelin-1 levels were similar in the 3 groups of fetuses.

In conclusion, fetal pulsatile bypass induced an increase in maternal $\mathrm{CO}$ as the result of a decrease in vascular peripheric resistances and a positive balance release of vasodilatator factors like NO.

\section{REFERENCES}

1. Elkayam Uri, Gleicher N. Hemodynamics and cardiac function during normal pregnancy and the puerperium. In: Elkayam U, Gleicher N, editors. Cardiac problems in pregnancy: diagnosis and management of maternal and fetal disease. 2nd ed. New York: Alan R Liss; 1990. p.5-30.

2. Broughton-Pipkin F, Morrison R, O'Brien PM. Prostacyclin attenuates both pressor and adrenocortical response to angiotensin II in human pregnancy. Clin Sci 1989;76:529-34.

3. Brown MA, Zammit VC, Adsett D. Stimulation of active renin release in normal and hypertensive pregnancy. Clin Sci 1990;79:505-11.

4. Gazzaniga A. Cardiac surgery during pregnancy. In: Elkayam $\mathrm{U}$, Gleicher N, editors. Cardiac problems in pregnancy: diagnosis and management of maternal and fetal disease. 2nd ed. New York: Alan R Liss; 1990. p.259.

5. Fenton KN, Zinn HE, Heinemann MK, Liddicoat JR, Hanley FL. Long-term survivors of fetal cardiac bypass in lambs. J Thorac Cardiovase Surg 1994;107:1423-7.

6. Fenton KN, Heinemann MK, Kickey PR, Klautz RJM, Liddicoat JR, Hanley FL. Inhibition of the fetal stress response improves cardiac output and gas exchange after fetal cardiac bypass. J Thorac Cardiovasc Surg 1994;107: 1416-22.

7. Hawkins JA, Paape KL, Adkins TP, Shaddy RE, Gay WA.
Extracorporeal circulation in the fetal lamb: effects of hypothermia and perfusion rate. J Cardiovasc Surg 1991;32:295300 .

8. Sabik JF, Assad RS, Hanley FL. Prostaglandin synthesis inhibition prevents placental dysfunction after fetal cardiac bypass. J Thorac Cardiovasc Surg 1992;103:733-42.

9. Sabik JF, Heinemann MK, Assad RS, Hanley FL. High-dose steroids prevent placental dysfunction after fetal cardiac bypass. J Thorac Cardiovase Surg 1994;107:116-25.

10. Champsaur G, Parisot P, Martinot S, Ninet J, Robin J, Ovize $\mathrm{M}$, et al. Pulsatility improves hemodynamics during fetal bypass. Circulation 1994;90(part 2):II47-50.

11. Champsaur G, Vedrime C, Martinot S, Trone F, Robin J, Ninet J, et al. Flow-induced release of EDRF during pulsatile bypass: experimental study in the fetal lamb. $\mathbf{J}$ Thorac Cardiovasc Surg 1997;114:738-44.

12. Pohl U, Holtz J, Busse R, Bassenge E. Crucial role of endothelium in the vasodilator response to increased flow in vivo. Hypertension 1986;8:37-44.

13. Pohl U, Busse R, Kuon E, Bassenge E. Pulsatile perfusion stimulates the release of endothelial autocoids. J Appl Cardiol 1986;1:215-35.

14. Rubanyi GM, Romero JC, Vanhoutte PM. Flow-induced release of endothelium-derived relaxing factor. Am J Physiol 1986;250:H1145-9.

15. Allevard AM, Gauquelin G, Gharib C. Endothelin and atrial natriuretic peptide after exercise performed until exhaustion in the rat. Life Sci 1991;49:1803-8.

16. Conrad KP, Joffe GM, Kruszyna H, Kruszyna R, Rochelle LG, Smith RP, et al. Identification of increased nitric oxide biosynthesis during pregnancy in rats. FASEB J 1993; 7:56671.

17. Fineman JR, Heymann MA, Soiffer SJ. $N^{\omega}$-nitro-L-arginine attenuates endothelium-dependent pulmonary vasodilation in lambs. Am J Physiol 1991;260:H1299-306.

18. Philbin DM, Levine FH, Kono K, Coggins CH, Moss J, Slater EE, et al. Attenuation of the stress response to cardiopulmonary bypass by the addition of pulsatile flow. Circulation 1981;64:808-12.

19. Downing SW, Edmunds LH. Release of vasoactive substances during cardiopulmonary bypass. Ann Thorac Surg 1992;54:1236-43.

20. Landymore RW, Murphy DA, Kinley CE, Parrott JC, Moffitt EA, Longley WJ, et al. Docs pulsatile flow influence the incidence of postoperative hypertension? Ann Thorac Surg 1979:28:261-8.

21. Salerno TA, Henderson M, Keith FM, Charette EJP. Hypertension after coronary operation. Can it be prevented by pulsatile perfusion? J Thorac Cardiovasc Surg 1981;81:396-9.

22. Vanhoutte PM, Boulanger CM, Monbouli JV. Endotheliumderived relaxing factors and converting enzyme inhibition. Am J Cardiol 1995;76:3E-12E.

23. Hecker M, Mülsch A, Bassenge E, Busse R. Vasoconstriction and increased flow: two principal mechanisms of shear stress-dependent endothelial autocoid release. Am J Physiol 1993;265:H828-33

24. Nollert MV, Diamond SL, Mclntire LV. Hydrodynamic shear stress and mass transport modulation of endothelial cell metabolism. Biotechnol Bioengin 1991;38:588-602.

25. Rudolph AM. Distribution and regulation of blood flow in the fetal and neonatal lamb. Circ Res 1985;57:811-21. 
26. Conrad KP, Vill M, McGuire PG, Dail WG, Davis AK. Expression of nitric oxide synthase by syncytiotrophoblast in human placental villi. FASEB J 1993;7:1269-76.

27. Myatt L, Brawer AS, Langdon G, Brockman DE. Attenuation of the vasoconstrictor effects of thromboxane and endothelin by nitric oxide in the human fetal-placental circulation. Am J Obstet Gynecol 1992;66:224-50.

28. Diket A, Pierce M, Munshi U, Voelker C, Greenberg S, Zhang $X J$, et al. Nitric oxide inhibition causes intrauterine growth retardation and hind-limb disruptions in rats. Am J Obstet Gynecol 1994;171:1243-50.

29. Sakurai T, Goto K. Endothelins: vascular actions and clinical implications. Drugs 1993;46:795-804.

30. Mondon F, Mallassine A, Robaut C, Vial M, Bandet J, Tanguy G, et al. Biochemical characterization and autoradiographic localization of endothelin 1 binding sites on trophoblast and blood vessels of human placenta. $\mathbf{J}$ Clin Endocrinol Metab 1993;76:237-44

\section{Bound volumes available to subscribers}

Bound volumes of The Journal of Thoracic and Cardiovascular Surgery are available to subscribers (only) for the 1998 issues from the Publisher, at a cost of $\$ 122.00$ for domestic, $\$ 151.94$ for Canadian, and $\$ 142.00$ for international subscribers for Vol 115 (January-June) and Vol 116 (July-December). Shipping charges are included. Each bound volume contains a subject and author index and all advertising is removed. Copies are shipped within 60 days after publication of the last issue of the volume. The binding is durable buckram with the Journal name, volume number, and year stamped in gold on the spine. Payment must accompany all orders. Contact Mosby, Inc, Subscription Services, 11830 Westline Industrial Drive, St Louis, Missouri 63146-3318, USA; phone $800-453-4351$ or $314-453-4351$.

Subscriptions must be in force to qualify. Bound volumes are not available in place of a regular Journal subscription. 